\title{
The Evolution of Measles in Romania Between 2016 and 2018 A comprehesive overview
}

\begin{abstract}
SIMONA NICOLETA MUSAT ${ }^{1,2}$, MARIA ROXANA NEMES ${ }^{2}$, COSMIN ALEC MOLDOVAN²*, TUDOR HARSOVESCU², IOAN SORIN TUDORACHE², ALEXANDRA FLORIANA NEMES ${ }^{3}$, LAURA ION², ELENA RUSU²

${ }^{1}$ National School of Public Health, Management and Professional Development, 31 Vaselor Str., 030167, Bucharest, Romania ${ }^{2}$ Titu Maiorescu University, Faculty of Medicine, Preclinic Department, 67A Gheorghe Petrascu Str., 031593, Bucharest,Romania ${ }^{3}$ Carol Davila University of Medicine and Pharmacy, Faculty of Medicine, 8 Eroii Sanitari Blvd, 050474, Bucharest, Romania

Measles is an ever-growing threat, a major public health issue, being responsible for a large number of deaths, especially in children. This paper aims to study all cases of measles in Romanian hospitals, cases reported by National School of Public Health, Management and Professional Development, Bucharest on a two year period of time; the study focuses on frequency and pattern territorial distribution of cases, temporal evolution, complication rates and the social pressure the such an infectious disease is putting onto the national health system. Data gathered shows a total number of 2,985 for 2016, 10,181 for 2017 and 8,364 for the entire 2018, with a grand total of 21,530 patients analyzed by our study. The analysis clearly shows, on one hand, a descending rate in vaccination coverage, compared with the national assigned target and, on the other hand, a continuous drop in vaccination rates with the first dose of Measles-mumps-rubella vaccine (MMR), both being in equal manner dangerous situations for the entire health system in Romania.
\end{abstract}

Keywords: measles, evolution, vaccination rate

Measles continue to represent a major public health problem, being responsible for many deaths in children, despite the fact that modern medicine provides a simple and effective method of preventing it.

Measles, an eruptive disease, with high contagious rate, is determined by a virus belonging to the Paramyxoviridae family, transmitted diseases. After a period of incubation of 10 to 11 days, the condition begins with fever, altered general condition, mule, conjunctivitis, characteristic enanthem, followed shortly after the occurrence of eruption.

The virus is transported to draining lymphoid tissues, seeding a systemic infection with preferential tropism to $B$ and T-lymphocytes. The incubation period is estimated to last 10 to 14 days, and is associated with leukopenia. Rash is generally observed from three to five days following onset of fever. Individuals are considered to be infectious from approximately four days before rash to four days after rash onset. Diagnosis is based on recognizing the clinical picture and can be confirmed with results of laboratory testing, such as serologic tests or polymerase chain reaction. Total uncomplicated disease course is 17-21 days from first sign of fever [1]. Measles infection leads to immune suppression for weeks to months.

The risk of measles morbidity and mortality is multifactorial, depending on both vaccination and nutrition status; malnutrition and vitamin A deficiency are risk factors for severe outcomes [2,3]. Vitamin A deficiency is associated with increased mortality. To protect against the consequences of vitamin A deficiency the World Health Organization (WHO) recommends that high-dose vitamin A supplements be given together with routine vaccines to children between 6 months and 5 years of age in more than 100 low-income countries [4]. Other risk factors include being an infant who is too young to be vaccinated, being an unvaccinated or partially vaccinated individual, travelling to endemic areas, and exposure to sick individuals with fever and respiratory symptoms from endemic areas, household exposure, and immunodeficiency [5]. In temperate climates, measles is most common in late winter and early spring. Regarding MMR (Measles-mumpsrubella vaccine), the objective of the WHO Global Strategic Plan to eliminate measles and rubella (postponed to 2020) requires that the immunization coverage (IC) be higher than $95 \%$, with two doses required for children less than two years of age throughout each national territory. Vaccine coverage in excess of $95 \%$ interrupts endemic transmission of measles in many countries, but achievement of such coverage almost always requires coordinated supplementary mass vaccination campaigns [6].

In Romania, according to WHO vaccine-preventable diseases: monitoring system 2018 global summary, vaccination coverage in 2017 for the first dose was up to $87 \%$ and second dose of measles was up $75 \%$, in 2016 for first dose was up to $86 \%$ and for second dose was up to $76 \%$ [7]. According to the same global summary, in Romania were 9076 number of reported cases of measles in 2017 and 2435 cases in 2016.

Because symptoms regress most of the time within a week, there is a tendency for a large part of the population to tackle the disease superficially and neglect the possibility of complications. Most commonly these are due to respiratory over infection. Interstitial pneumonia or neurological complications with a reserved prognosis may occur, especially in the case of organisms that are already affected by previous immune deficits [8]).

Pneumonia is the most common cause of death in measles and common bacterial pathogens are Streptococcus pneumoniae, Haemophilus influenzae and Staphylococcus aureus. Other respiratory complications are: bronchiolitis, croup and tracheitis, sinusitis, acute otitis media and mastoiditis [9]. Complications occur in 10\% to $40 \%$ of patients, and treatment is mainly symptomatic. Measles is a highly contagious disease: up to $90 \%$ of susceptible contacts develop the disease. Even though the physiopathological mechanisms are yet to be understood, it appears that measles infection is affiliated with transitory immunosuppression lasting weeks to months. Transitory

* email: moldovan.cosmin@gmail.com, Phone: 0040723504207

All authors have equal contribution to the study and the publication 
immunosuppression appears after poisoning as well [1012]. Transitory immunosuppression predisposes to secondary infections, especially in the respiratory tract with different pathogens, such as M.tuberculosis and gastrointestinal tract [13-16].

The lack of specific treatment of the disease stresses once again the importance of the prevention, the turntable of which is vaccination. The WHO estimated that in 2000 recorded a loss in lives due to measles of 535.000 children, most from developing countries, which represented $5 \%$ of all deaths under the age of 5 years. On the other hand, in the period 2000 - 2016, due to vaccination, the percentage of deaths caused by measles decreased by $84 \%$ [ 9 ].

Starting from these findings and recognizing their importance as public health problems, the WHO developed a Strategic Plan for 2012-2020 periods, on measles and rubella. It was provided that, by the end of the year 2015, the incidence of measles should have values below 5 cases in 1 million inhabitants, and the first dose vaccination rate to be at least $90 \%$ at national level and at least $80 \%$ at the area (county) level, while by the end of 2020 a vaccine coverage of $95 \%$ was suggested for both doses at both national level and area levels [10].

The analysis of the situation in our country, according to data published by the National Centre for Monitoring and Control of Transmitting Diseases (NCMCTD), shows, on the one hand, a vaccine coverage rate less than the target proposed, and on the other hand a continuous decrease of vaccination rate with the first dose of MMR [18], as shown in figure 1. These findings might suggest a gradual accumulation of a critically responsive mass in the population and, as a result, the creation for conditions for the outbreak of the epidemic in early 2017 [19].

\section{Experimental part}

This paper aims to study the cases of measles admitted in hospitals in Romania and reported back to the National School of Public Health, Management and Professional Development, Bucharest (NSPHMPDB) during 01.01.201631.10 .2018 , in order to analyze the frequency and territorial distribution, temporal evolution, rate of complications and the economic burden that such a preventable disease, by means of vaccination, puts on the health care system. As a side note,for 2018, by the time this paper has been developed, only hospitalized cases in the first 10 months were available for complete analysis.

\section{Results and disscussions}

At national level, from the outbreak of the epidemic to the present time, the number of cases of hospitalized measles recorded two peaks, in March-J une 2017 and March-J une 2018 respectively, which could be associated more likely to the seasonality of the disease. Never the less, following the measures taken by the Ministry of Health, in the year 2017,that started mapping all the children eligible for contacting the disease and decided to administer an additional dose of vaccine from the age of 9 months. These actions, alongside with the possible exhaustion of the responsive mass, can explain the decrease in the number of measles cases in October 2018 at values comparable to those at the beginning of 2016 , as illustrated in figure 2.
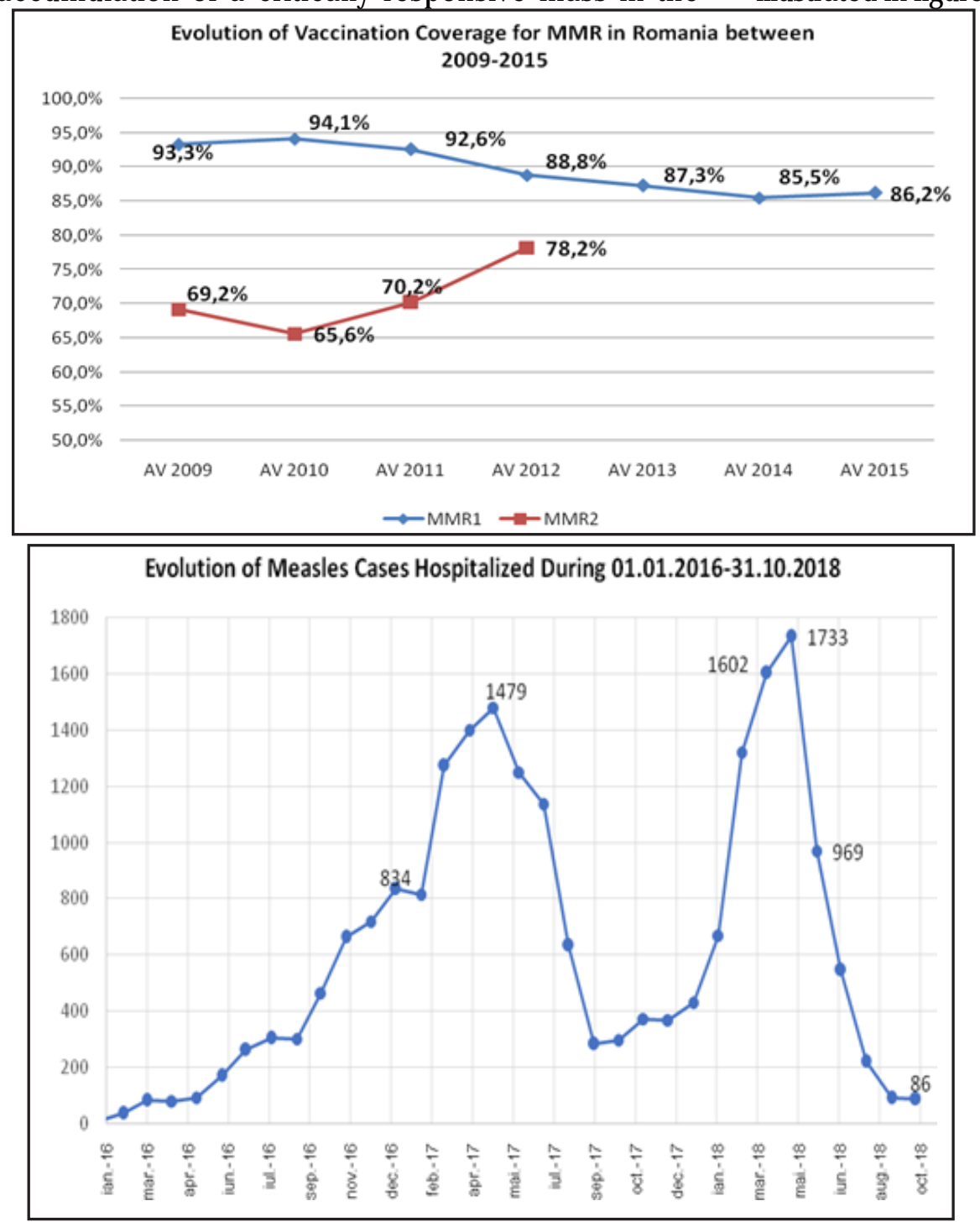

Fig. 1. Evolution of vaccination coverage for MMR, estimated by NCMCTD for Romania, between 2009-2015

Fig. 2. Measles cases hospitalized between 2016-2018 (Data source: as provided by NSPHMPDB) 
Regarding the territorial distribution, at the county level, as published by National Center for Surveillance and Control of Communicable Diseases (CNSCBT) from the beginning of the epidemic and up to present time [20], linked with the analyzed data, the highest rates of hospitalization recorded in the counties with the highest incidence of measles were Arad, Caras-Severin, Timis, Satu-Mare, Brasov and Calarasi.

The number of hospital episodes is higher than that of patients, in partbecause there have been records for which no encrypted personal ID number has been reported (and for which no distinct identification of patients can be achieved), and due to the readmissions.

Because by the time this study was drafted data only from the first 10 months of 2018 were available, a projection of the number of cases and patients for this year was made in order to carry out the analysis. From the data obtained so far, itseems that the number of total hospitalized patients for measles or its direct complications at national level was 2.985 in 2016, 10.181 in 2017 and 8.364 throughout the year 2018. The most marked descending trend is recorded for the age group 1-5 years, as is apparent from figure 3 .

The fact that the number of children under 1 year who were hospitalized for measles in 2018 is almost equal to that of 2017, might suggest that those who have already contacted the disease in 2016 or 2017 have passed into the upper age group, rather than being a result of a real efficacy campaign to promote vaccination or the additional dose introduced at the age of 9 months. However, an analysis at an additional level of detail shows a decrease in the protection of measles cases of 2018 for children over the age of 11 months (figure 4), which may be related to the installation of the subsequent dose administered at nine months. As the number of children under the age of 9 months who developed the disease is still high, even if the clinical forms could be milder by the existence of transplacental immunity, it shows that for them the only effective measure of prevention is the extinction of the epidemic.

Over the three years analyzed, the share of cases discharged as aggravated or even reported as deaths was $2 \%$ in $2016,2.4 \%$ in 2017 and $2.9 \%$ in 2018. The detailed situation of the deaths of hospitalized patients for measles is rendered in table no. 1 and it shows that most of them are registered under the age of 5 , in patients with associated pathology, and during the epidemic a particularly affected age group is 0-6 months.

The readmission rate was relatively equal for all three years analyzed, by approximately $1.1 \%$, but even though most patients were hospitalized once, the maximum number of admissions for the same patient for measles or complications was 6 in 2016, of 9 in 2017 and 13 in 2018. Measles without complications was recorded as a primary diagnosis for patients in proportions ranging from $9.4 \%$ to
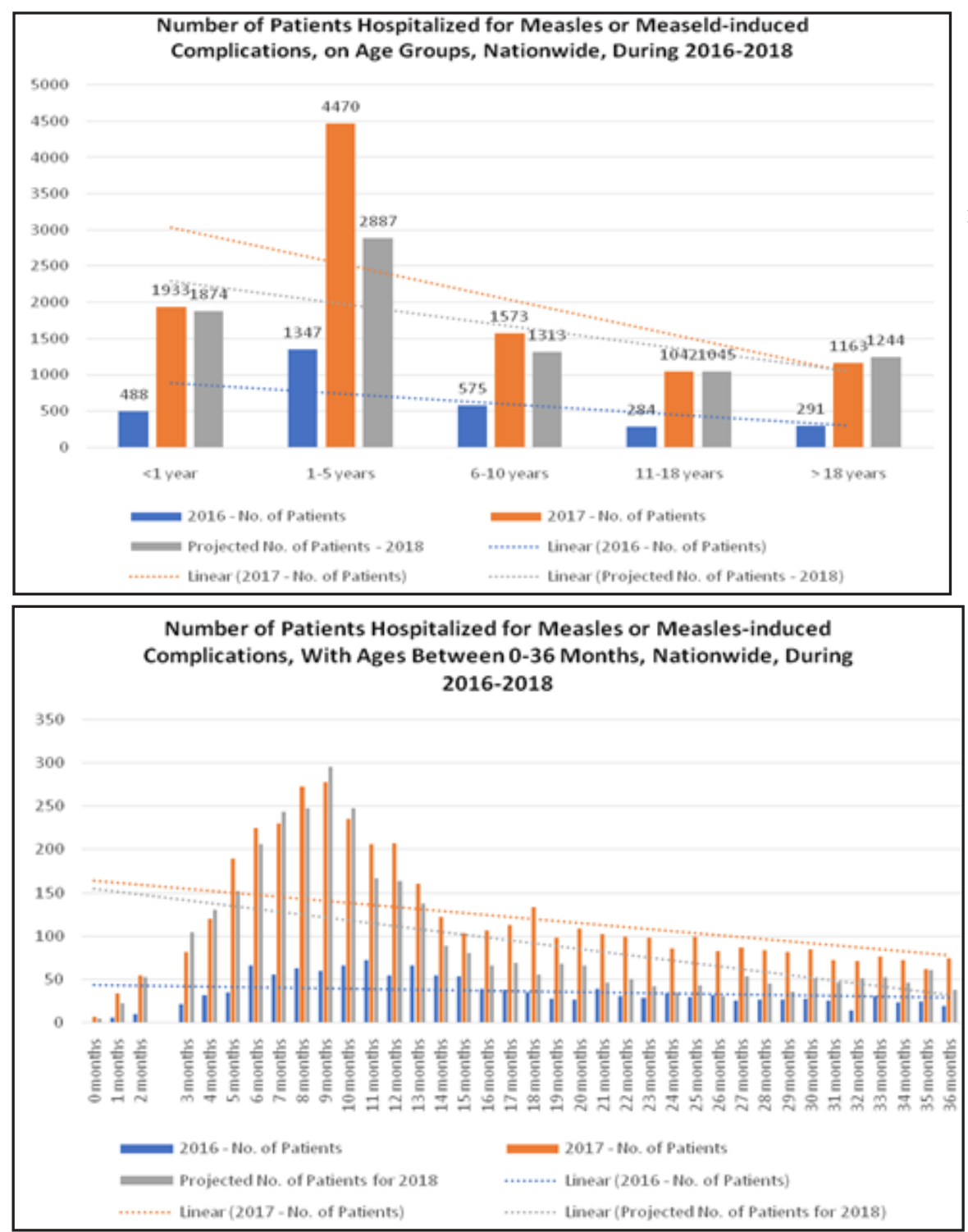

Fig. 3.Number of patients hospitalized for measles or measles-induced complications, on age groups, nationwide, during 20162018.Data was provided by NSPHMPDB

Fig. 4. Number of patients hospitalized for measles or measles-induced complications, with ages between 0-36 months, nationwide, during 2016-2018.

Data was provided by NSPHMPDB 
Table 1

DETAILED SITUATION OF DEATHS, ON AGE GROUPS, NATIONWIDE, BETWEEN 01.01.2016 - 30.10.2018. DATA WAS PROVIDED BY NSPHMPDB

\begin{tabular}{|c|c|c|c|}
\hline \multirow{2}{*}{ Age } & \multicolumn{3}{|c|}{ Years } \\
\cline { 2 - 4 } & $\mathbf{2 0 1 6}$ & $\mathbf{2 0 1 7}$ & $\mathbf{2 0 1 8}$ \\
\hline 0-6 months & 0 & 10 & 7 \\
\hline 7-11 months & 2 & 6 & 8 \\
\hline 1-5 years & 5 & 7 & 4 \\
\hline 6-10 years & 0 & 1 & 0 \\
\hline 11-18 years & 2 & 0 & 0 \\
\hline >18 years & 1 & 2 & 1 \\
\hline Total & $\mathbf{1 0}$ & $\mathbf{2 6}$ & $\mathbf{2 0}$ \\
\hline
\end{tabular}

$20.7 \%$ during the 3 years analyzed, instead, measles complicated with pneumonia reached rated between $41.7 \%$ and $52.8 \%$. It is also worth mentioning that for the latter category of cases the average hospitalization times were almosta day longer than in the case of uncomplicated measles.

In the age group 0-6 months the most common secondary diagnosis recorded during the years considered were stomatitis by Candida, acute respiratory failure, hypovolemia and diarrhea, while for adult patients prevailed hepatitis,urinary tract infections and possibly infectious diarrhea. Increased attention was given to hospitalized patients with complicated measles with pneumonia due to the increased frequency and severity of some cases. As rendered in figure no. 5 more than $50 \%$ of measles patients experienced pulmonary complications during the period considered, these cases achieved average hospitalization durations between 6.4 and 6.7 days. It is also worth mentioning among these patients the 4 deaths in 2016 (of which one under the age of 1 year), 16 deaths in 2017 (of which 11 under the age of 1 year) and 15 deaths in the first 10 months of 2018 (of which 12 below the age of 1 year).

Measles was associated with meningitis or encephalitis in 14 patients in 2016, in 24 patients in 2017 (one of them dying) and 25 patients in the first 10 months of 2018 . Severe malnutrition was an additional factor of gravity for 9 patients in 2016, 14 patients in 2017 and 3 patients in the first 10 months of 2018.
Sepsis with different microorganisms (Pseudomonas Aeruginosa, Staphylococcus Aureus, Candida Albicans or unspecified Gram-negative germs) was associated with a total of 5 patients in 2016 ( 3 of whom died), 18 patients in 2017 ( 1 of whom died) and 8 patients in the first 10 months of 2018. During 2016 there were 21 patients who had measles during pregnancy or birth, in 2017, 23 patients, and in the first 10 months of 2018, 28 such patients. During 2016, 15 patients with immunodepression due to HIV infection were reported, of which an adult died, during 201762 cases reported and in the first 10 months of 2018, 65 patients, of which an adult deceased.

The additional severity of the previously reported cases is highlighted not only by the already mentioned mortality but also by the fact that they have achieved higher hospitalization times than those with other associated pathologies, as it is rendered in chart no. 6. Furthermore, a higher hospitalization period generated notonly a potential additional risk of nosocomial infections, but also higher costs for the healthcare system.

In the age group 0-6 months such infections are predominantly caused by Candida albicans species and can affect the oropharynx and/or the esophagus of persons with dysfunctions of the adaptive immune system [2123]. Because simple changes in the physiology of the human organism can lead to disturbance of the balance in microbiota, the Candida genus species exhibit a very high pathogen profile [24-26]

In Surveillance Report pulished in October 2018, with a period covered between 1 September 2017 and 31 August 2018 is described the situation of measles in EU/EEA countries. The measles virus is exceptionally contagious and spreads easily among susceptible individuals. To prevent outbreaks, at least 95\% immunization coverage with 2 doses of measles-containing vaccine is needed every year in every community, as well as efforts to reach children, adolescents and adults who missed routine vaccination in the past. In Romania, according to Surveillance Report, vaccination coverage in 2017 for the first and second doses of measles was up to $84 \%$.

Between 1 September 2017 and 31 August 2018, 30 EU/EEA Member States reported 13547 cases of measles, of which $9364(69 \%)$ were laboratory-confirmed. The majority of cases were reported by Greece (3 171), France (2 792), Italy (2 718), Romania (1765) and United Kingdom (1 007), accounting for $23 \%, 21 \%, 20 \%, 13 \%$ and $7 \%$ of all

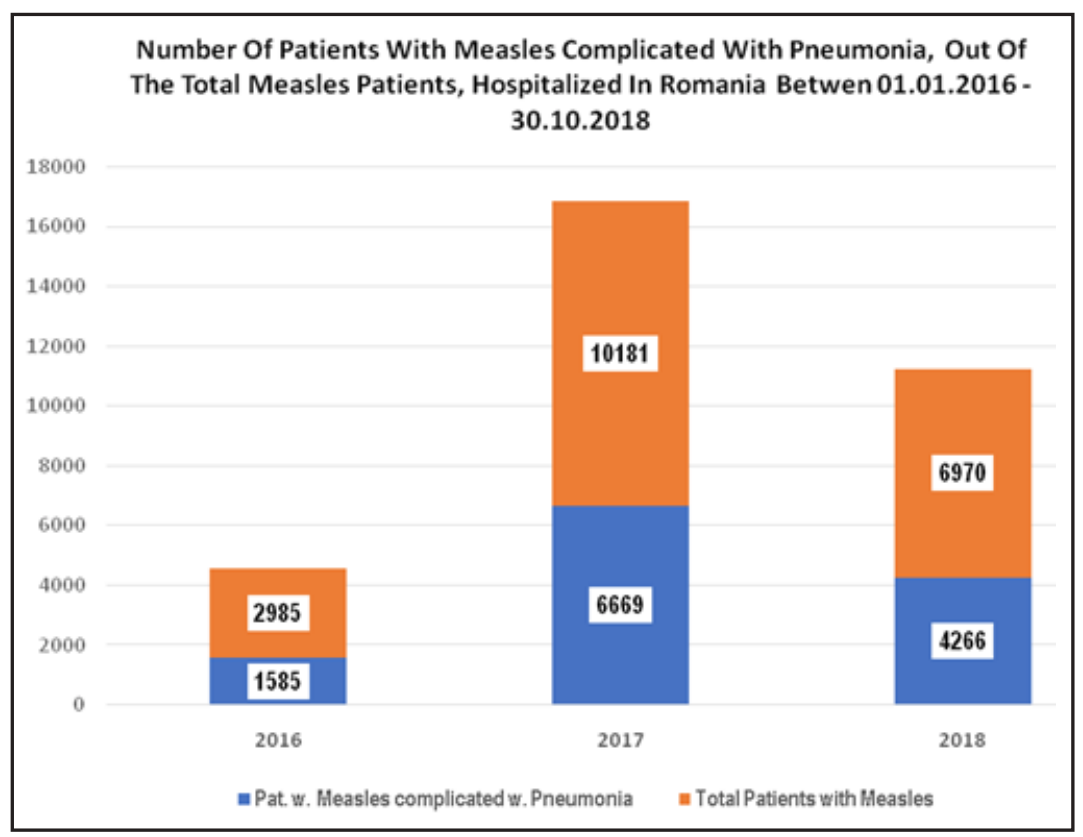

Fig. 5. Number of patients with measles complicated with pneumonia, out of the total measles patients, hospitalized in Romania between 01.01.2016 - 30.10.2018. Data was provided by NSPHMPDB 


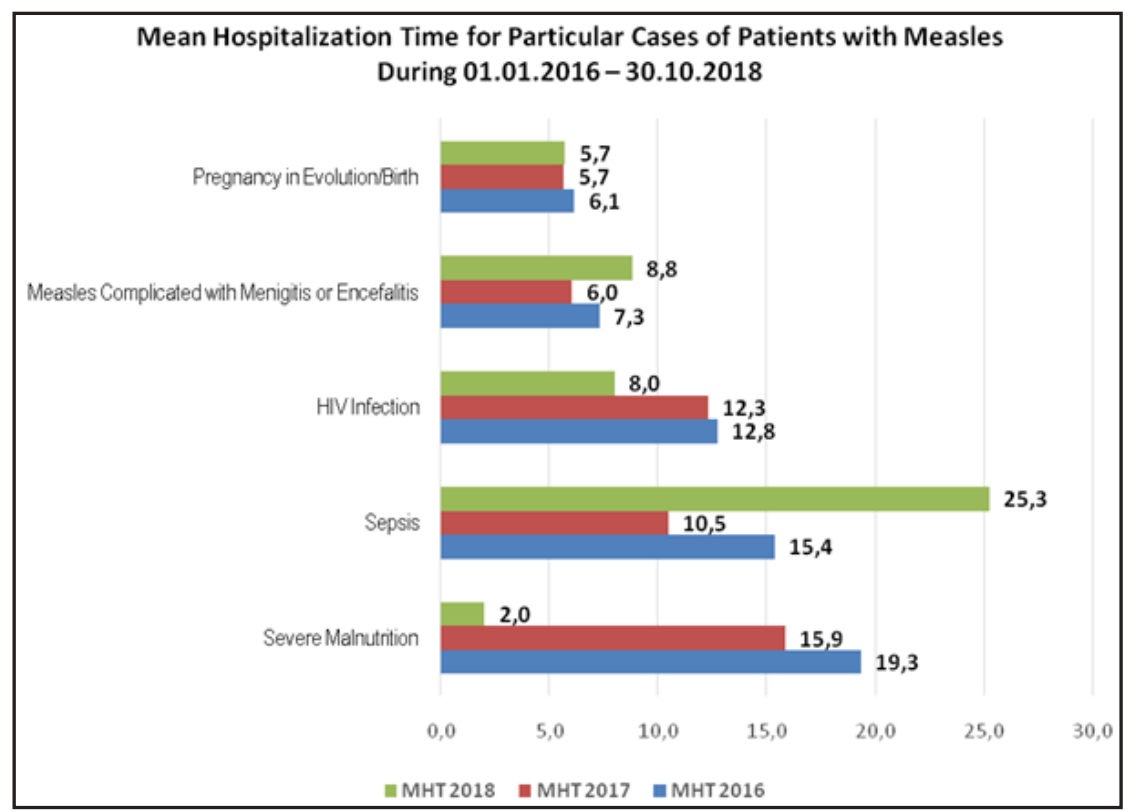

Fig. 6. Mean hospitalization time for particular cases of patients with measles during 01.01.2016 - 30.10.2018. Data was provided by NSPHMPDB

cases respectively. Notification rates per million populations above the EU/EEA average (26.2) were reported by Greece (294.5), Romania (89.8), Slovakia (81.5), Italy (44.9) and France (41.7) [27]. According to this report, in Romania was registered the highest rate of mortality, with 24 death cases in Romania from 38 measles deaths in EU/EEA in reported period.

In Romania, vaccination coverage in 2017 for the first dose was up to $87 \%$ and second dose of measles was up $75 \%$, in 2016 for first dose was up to $86 \%$ and for second dose was up to $76 \%$ and 9076 in 2017 and 2435 cases in 2016 number of reported cases [7]. In the region, in Bulgaria, the vaccination coverage in 2017 for the first dose was up to $94 \%$ and second dose of measles was up $92 \%$, in 2016 for first dose was up to $92 \%$ and for second dose was $88 \%$, and reported cases were 165 and 1, respectively. In Serbia for first and second dose the vaccination coverage was $86 \%$ and $91 \%$ in 2017, and $82 \%$ and $90 \%$ in 2016 and reported cases were 721 and 11 . In Hungary, where the vaccination coverage for measles in both years was 100\%, number of reported cases was 36 in 2017 and 0 in 2016.

In France, the vaccination coverage for measles was $90 \%$ and $80 \%$ for first and second dose in both years, with a number of cases reported 519 in 2017 and 79 in 2016. Until the end of 2017, the French vaccination schedule which makes the distinction between obligation and recommendation difficult to understand for both health professionals and the general population combined mandatory and recommended vaccinations [28]. In Italy, in 2017 the vaccination coverage was $92 \%$ and $86 \%$ for first and second dose, respectively, with 4042 cases reported in 2017. In May 2017, Italy extended its vaccination requirements to include the measles. For 2016 is no report for Italy. In United Kingdom, the data were $90 \%$ and $88 \%$ in 2017 for first and second dose and $92 \%$ and $89 \%$ in 2016; the numbers of reported cases were 364 in 2017 and 558 in 2016.

For this data we observed the vaccination coverage is very important, and the number of cases reported is related with value. Immunization is the key to the elimination of measles and the measles vaccine is highly effective and considered extremely safe, but misinformation about the safety of this and other vaccines has decreased immunization coverage in some areas of the country. Multiple studies have found no causal link between vaccination and autism, but the falsified report continues to cause parental concern [29]. Physicians must acknowledge these fears and inform concerned parents about the benefits of immunization and the potential harm of vaccine refusal. Infection with measles causes more severe adverse effects than the MMR vaccine [30]. Parental misconceptions about vaccine safety are a serious problem. Some parents consider vaccinations unnecessary, believing their children won't be exposed to measles. To provide accurate information and accurately answer parents' questions about vaccine and its safety, physicians must be familiar with the current status and global and local prevalence of vaccine-preventable diseases in general, current vaccination recommendations, and vaccines' risks and benefits.

Physicians can play an important role in increasing vaccine coverage. Numerous studies have shown that interventions and advice from health professionals improve vaccine acceptance. To correct the poor implementation of some vaccination programs by health professionals, strong communication and resources from health authorities are needed. Health care professionals also play an important role in uptake of measles vaccination through establishing trusting relationships with parents, offering vaccination at indicated times, and engaging parents in discussion on facts and concerns about vaccination [31].

\section{Conclusions}

The currentmeasles epidemic in Romania brought with it very high costs, both in terms of human life and the financial resources required for hospitalization of such a large number of patients, without mentioning the increased risk for late complications such as subacute sclerotic panencephalitis (SSP), which although rare (4-11 cases in 100,000 people who contracted the disease), has a dismal prognosis [20]. In the context of children less than 9 months of age have a relatively high risk of contracting the disease and possibly developing complications, we believe that it is imperative to intensify the nation-wide campaigns to promote vaccination and to take all necessary measures for our country to reach the vaccination coverage targets proposed by WHO.

\section{References}

1.COUGHLIN, MM., BECK, AS., BANKAMP, B., ROTA, PA., Viruses, 9, nr.1, 2017, pii: E11. doi: 10.3390/v9010011. 
2.HAGAN, JE., TAKASHIMA, Y., SARANKHUU, A., DASHPAGMA, O., et all., J, Infect, Dis, 216, nr. 10, 2017, p.1187

3.BALE, C., GARLY, ML., MARTINS, C., NIELSEN, J., WHITTLE, H., AABY, P., Pediatr, Infect, Dis, J, 30, nr. 8, 2011, p.689

4.BENN, CS., Dan, Med, J, 59, nr.1, 2012, p.B4378.

5.LEUNG, ACK., HON, KL., LEONG, KF., SERGI, CM., Hong Kong Med, J, 24, nr. 5, 2018, p.512

6.DUKE, T., MGONE, CS., Lancet. 361, nr. 9359, 2003, p.763

7.*** http://apps.who.int/immunization_monitoring/globalsummary/ countries?countrycriteria $\% 5$ Bcountry $\% \overline{5} \mathrm{D} \% 5 \mathrm{~B} \% 5 \mathrm{D}=\mathrm{ROU}$

8.LIYANAGE, HJ D., FAIZAL, MAM., KANANKEARACHCH, KPP., Sri Lanka J, Child Health, 45, nr. 3, 2015, p.215

9.KLIEGMAN, R., NELSON, WE., Nelson textbook of pediatrics. Philadelphia, PA: Elsevier/Saunders; 2011.

10.NITESCU, V., BOGHITOIU, D., NICOLAESCU, R., PASLARU, C.A., ULMEANU, C., Clinic. Toxicol. 57, nr.6, 2019, p.446

11.NITESCU, V.G., ULMEANU, A.I., ULMEANU, C.E., Clinic. Toxicol., 48, nr.3, 2010, p.276

12.ULMEANU, C.E., NITESCU, V.G., ULMEANU, A.I., Clinic. Toxicol., 48, nr.3, 2010, p.291

13.NEMES, R.M., POP, C.S., CALAGIU, D., DOBRIN, D., CHETROIU, D., JANTEA, P., et al. Rev. Medico-Chir. Soc. Med. Iasi., 120, nr.1, 2016, p.34.

14.NITU, M.F., OLTEANU, M., STREBA, C.T., JIMBOREAN, G., POSTOLACHE P., MAN, M.A., TROFOR, A.C., NEMES, R.M., DRAGONU, L., OLTEANU, M., Rom. J. Morphol. Embryol., 58, nr.2, 2017, p.385 15.DE VRIES, R.D., MESMAN, A.W., GEIJTENBEEK, T.B.H., DUPREX, W.P., DE SWART, R.L., Curr. Opin. Virol., 2, nr. 3, 2012, p.248

16.WHITTAKER, E., LOPEZ-VARELA, ELISA., BRODERICK, CLAIRE., SEDDON, J.A., Frontiers in Pediatrics, nr 7, 2019, p.233

17.*** WHO. Measles. Key Facts. Feb. 2018 http://www.who.int/ newsroom/factsheets/detail/measles

18.*** WHO. Global Measles and Rubella Strategic Plan 2012-2020.

2012 http://apps.who.int/iris/bitstream/handle/10665/44855/ 9789241503396_eng.pdf; jsessionid=642771AB623B1827EDF5CF CD72275FC9?sequence $=1$
19.*** CENTRUL NATIONAL PENTRU SUPRAVEGHEREA SI CONTROLUL BOLILOR TRANSMISIBILE. Estimarea acoperirii vaccinale. 2014, 2015, 2016, 2017, 2018 https://cnscbt.ro/index.php/analiza-datesupraveghere/evaluarea-acoperirii-vaccinale

20.*** CENTRUL NATIONAL PENTRU SUPRAVEGHEREA SI CONTROLUL BOLILOR TRANSMISIBILE. Situatia rujeolei în Romania la data de 02.11.2018. https://cnscbt.ro/index.php/informari-saptamanale/rujeola1/1015-situatia-rujeolei-in-romania-la-data-de-02-11-2018/file

21.RUSU, E., SARBU, I., MITACHE, M., MOLDOVAN, H., BIRIS, Cl., VASSU, T., PELINESCU, D., Rev. Chim. (Bucharest), 68, no. 11, 2017, p. 2566

22.MITACHE, MM., CURUTIU, C., RUSU, E., BAHA, R, DITU, M., MOLDOVAN, H., HANCU, V., CHIFIRIUC, MC., Rev. Chim. (Bucharest), 68, no.3, 2017, p.566

23.MITACHE, MM., GHEORGHE, I., TOTEA, G., BLEOTU, C., CURUTIU, C., COCHIOR, D., RUSU, E., CHIFIRIUC, MC., Rev. Chim. (Bucharest), 68, no.5, 2017, p.997

24.RUSU, E., MOLDOVAN, C.A., MITACHE, M.M., NICULAE, M., POPESCU, G.G., NEMES, R.M., Rev. Chim. (Bucharest), 70, no. 1, 2019, p.129

25.SARBU, I., VASSU, T., CHIFIRIUC, M.C., BUCUR, M., STOICA, I., PETRUT, S., RUSU, E., MOLDOVAN, H., PELINESCU, D., Rev. Chim. (Bucharest), 68, no. 12, 2017, p.3015

26.IANOSI, E.S., DANTES, E., CSIPOR, A., SZATHMARY, M., SOCACI, A., RUSU, E., NEMES, RM., Rev. Chim. (Bucharest), 69, no. 10, 2018, p. 2725

27.*** https://ecdc.europa.eu/sites/portal/files/documents/measlesrubella-monitoring-report-october-2018.pdf

28.PARTOUCHE, H., GILBERG, S., RENARD, V., SAINT-LARY O., EJGP, 25, nr. 1, 2019, p.49

29.GODLEE, F., SMITH, J., MARKOVITCH, H., BMJ, 342, c7452, 2011, doi: $10.1136 /$ bmj.c 7452 .

30.SPENCER, JP, TRONDSEN, PAWLOW SKI, RH., THOMAS, S., Am, Fam, Physician, 95, nr. 12, 2017, p.786

31.BESTER, JC., JAMA Pediat, 170, nr. 12, 2016, p.1209

$\overline{\text { Manuscript recewived: } 15.08 .2019}$ 